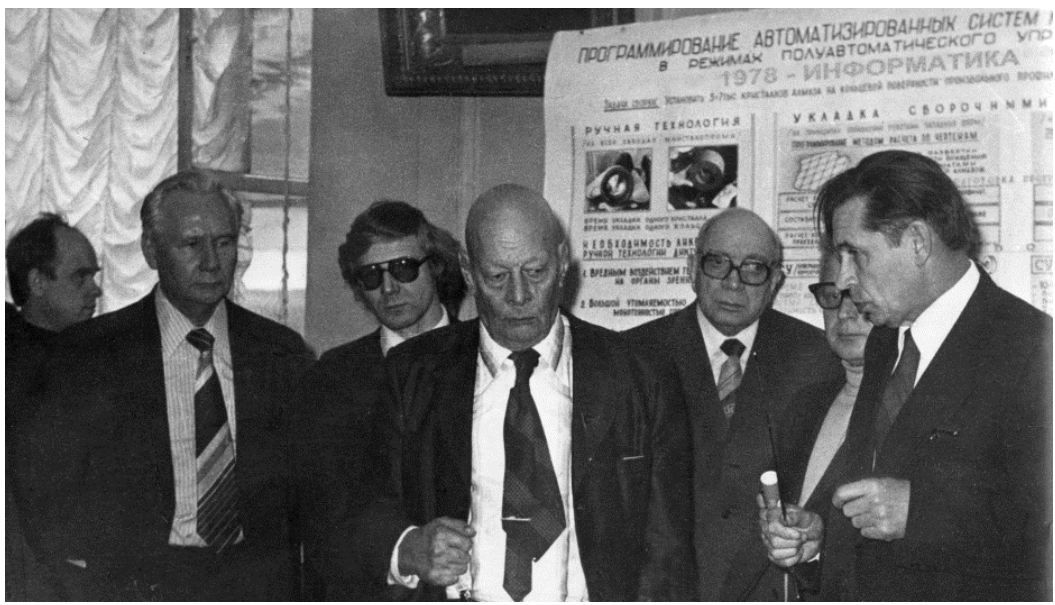

В.М. Пономареву, Создателю в Ленинграде первого в России института информатики

УДК 004.81:004.9

\title{
В.В. АЛЕКСАНДРОВ
}

\section{МАТЕМАТИКА. КИБЕРНЕТИКА. ИНФОРМАТИКА ${ }^{1}$}

Александров В.В. Математика. Кибернетика. Информатика.

Аннотация. В статье рассматривается смена парадигмы: от традиционных математических моделей теории управления $\mathrm{\kappa}$ алгоритмической теории информатики А.Н. Колмогорова. Проводится сопоставление между идентифицируемой объектной информацией и ансамблевой (энтропийной) информацией по Шеннону. Предложенные алгоритмические модели основаны на соответствующих приближениях ЗПК, рассматриваемых как самоподобные рекурсивные структуры (фрактальный подход).

Ключевые слова: информатика, инфология, информация, энтропия, алгоритмическая модель, эпистемология, единица разума, квант различимости.

\section{Alexandrov V.V. The Mathematics. The Cybernetics. The Informatics.}

Abstract. The article discusses the paradigm shift from traditional mathematical models of control theory to the A.N. Kolmogorov's algorithmic theory of computer science. A comparison between the identifiable object information and Shannon's ensemble (entropy) information. The proposed algorithmic models based on the respective approximations of space filling curves also regarded as self-similar recursive structure (fractal approach).

${ }^{1}$ Прим. ред.: Статья публикуется в авторской редакции в порядке дискуссии. 
Keywords: informatics, infology, information, enthropy, algorithmic model, epistemology, the unit of the mind, quant of distinguishability.

1. Преамбула. В науке все происходит так же ярко, так же беспечно и великолепно, как в сказке. Люди просто не знают этого; они понятия не имеют, как уже можно думать; если бы можно было научить их думать по-новому, они бы и жили иначе. Возникает, правда, вопрос: так ли уж все неправильно в мире, что его нужно то и дело переворачивать? Но на это мир давно сам дал два ответа. Ведь с тех пор, как он существует, большинство людей были в юности за то, чтобы его перевернуть. Они находили смешным, что старшие привязаны к существующему и думают сердцем, куском мяса, вместо того чтобы думать мозгом. Эти молодые всегда замечали, что моральная тупость старших есть в такой же мере неспособность к новому, как обыкновенная интеллектуальная тупость, и естественная для них самих мораль была моралью продуктивности, героизма и перемен. Однако, придя в возраст свершений, они больше не вспоминали об этом, да и вспоминать не желали. Вот почему многие, для кого математика означает профессию, сочтут это наглостью.

\section{Музиль Р. «Человек без свойств» [1]}

2. Вехи нашего пути. Лаборатория автоматизации научных исследований была создана, в составе вновь образуемой академической организации - в будущем СПИИРАН, его основателем и первым директором В.М. Пономаревым еще в 1974 году. Заведующим лабораторией был приглашен В.В. Александров, в то время кандидат технических наук, работавший над докторской диссертацией по тематике, связанной с поиском новых решений в области анализа и обработки данных.

В дальнейшем в серии работ В.В. Александрова с сотрудниками предпринимается теоретический анализ возможностей технических приложений функций Вейерштрасса (ЗПК). При этом объектом изучения в явном виде становятся уже не заполняющие пространство кривые, а соответствующие приближения, рассматриваемые как самоподобные рекурсивные структуры (фрактальный подход). Более подробно в [2].

Основные публикации:

1. Александров В.В., Горский Н.Д. Алгоритмы и программы структурного метода обработки данных. М.: Наука, 1982.

2. Александров В.В., Арсентьева А.В. Информация и развивающиеся структуры. Л.:ЛНИВЦ, 1984. 
3. Александров В.В., Горский Н.Д. Представление и обработка изображений. Рекурсивный подход. Л., Наука, 1985.

4. Alexandrov V.V., Gorsky N.D. Image Representation and Processing. A Recursive Approach. Amsterdam, Kluwer Academic Publishers, 1993.

5. Alexandrov V.V., Gorsky N.D. From Humans to Computers: Cognition through Visual Perseption. Singapore, World Scientific, 1991.

6. Александров В.В. Развивающиеся системы. В науке, технике, обществе и культуре: ч.I. Теория систем и системное моделирование. СПб.: Изд-во СПбГТУ, 2000.

7. Александров В.В. Интеллект и компьютер. СПб.: Изд. «Анатолия», 2004.

8. Александров В.В., Андреева Н.А., Кулешов С.В. Системное моделирование. Методы построения информационнологистических систем / Учеб. пособие. СПб.: Изд-во Политехн. ун-та, 2006.

9. Александров В.В., Кулешов С.В., Цветков О.В. Цифровая технология инфокоммуникации. Передача, хранение и семантический анализ текста, звука, видео. СПб: Наука, 2008.

10. Научная школа «Алгоритмические модели цифровой программируемой технологии развивающихся инфокоммуникационных систем» // Информационно-измерительные и управляющие системы, №5, т. 10, 2012.

Цикл научно-популярных изданий в серии «ЭВМ для школьников» был отмечен премией ЦК ВЛКСМ в 1990 году:

- Александров В. В., Арсентьев В. Н., Арсентьева А. В. Что может ЭВМ? Под общ. ред. д-ра техн. наук В. В. Александрова. Л.: Машиностроение. Ленингр. отд-ние, 1988.

- Александров В.В.; Шнейдеров В.С. Рисунок, чертеж, картина на ЭВМ. Л.: Машиностроение, 1988.

- Александров В.В, Алексеев А.И, Семенков А.И. ЭВМ: игра и творчество. Л.: Машиностроение, 1989.

- Александров В.В., Горский Н.Д. ЭВМ видит мир. Л.: Машиностроение, 1990.

3. Математика и кибернетика. «Пока еще рано делать окончательные выводы о том, что это будет значить для общей архитектуры математики будущего» (А.Н. Колмогоров) [3]. В диспуте между Брауэром и Гильбертом [4] обсуждались 5 главных проблем: 
1) проблема непротиворечивости и полноты теории (математики), 2) обоснования теории, 3) существования математических объектов, 4) природы познания, 5) реальности и ее единства.

Проблема непротиворечивости и полноты теории.

Брауэр: классическая математика противоречива, т.к. опирается на теорию множеств, содержащую парадоксы. Новая (интуиционистская) математика рассматривает мир мысленных процессов, развертывающихся в последовательность элементарных актов (шагов). Результаты этих процессов — математические объекты и конструкции.

Гильберт: классическая математика непротиворечива, ее теории полны, т.к.

a) ее конструкции продуманы и признаны математическим сообществом;

б) она прекрасно работает на практике.

Бессмысленна замена классической математики на интуиционистскую, т.к. последняя неполна, это обрезанная (секвестированная) математика.

Проблема обоснования теории.

Брауэр: только такая математика обоснована, которая соответствует критериям интуиционизма как конструктивному обобщению человеческого опыта. Аксиоматический метод и формализация не выражают сущности математического мышления, т.к. скрывают за языковой формой эту сущность. Убедительное обоснование математики дает лишь интуиция как непосредственное внутреннее безъязыковое переживание образов, идущих из глубины «я». Лишь по требованию социума ученый вынужден облекать эти образы в языковую форму и тем искажать их.

Гильберт: классическая математика обосновывается коллективным опытом научного сообщества. Окончательное обоснование даст теория доказательств. Она является «протоколом о правилах мышления». Ее существенной частью являются формализм и аксиоматический метод.

\section{Проблема существования математических объектов.}

Брауэр: математический объект существует, если он построен явно или его построение возможно с помощью АЛГОРИТМА. (Современные знания ииифровых, информационных, квантовых технологий не обходятся без данного понятия алгоритма, но не следует понятие этого алгоритма отождествлять с алгоритмом аль Хорезми [5]). 
Гильберт: объект существует, если он непротиворечив. Доказательства существования сокращают и экономят мысль. Они всегда были вехами математического прогресса.

\section{Проблема природы познания.}

Брауэр: математическое мышление опирается на интуицию (прежде всего интуицию времени, интуицию раздвоения единого). Существуют исходные принципы мышления, но они лишь результат свободного творения математика-индивида. Изначально математическое исследование не зависит ни от языка, ни от логики. Главный метод мышления - интроспекция. Обыденное знание выше формального. Существуют неразрешимые проблемы.

Гильберт: математическое мышление основано на интеллектуальной ясности. До математики мы имеем опытные представления, конкретные объекты. Математика начинается со знаков, обозначающих эти объекты, и с логики, дающей надежные выводы. Математика интерсубъектна (является результатом коллективного творчества) и, вообще говоря, объективна. Формальное знание выше обыденного. Мир познаваем, все математические проблемы в принципе разрешимы. Нет никаких доказательств, что человек создан, чтобы решать математические проблемы.

\section{Проблема реальности и единства мира.}

Брауэр: реальность - это сознание индивида, это образы, мыслеформы, восходящие от внутренней сферы к внешнему миру. Это субъективная реальность. Существует ли объективная реальность, единая для всех индивидов, - открытый вопрос.

Гильберт: существует объективная реальность, данная нам наглядно, в качестве чувственных переживаний, до какого бы то ни было мышления. Единство мира проявляется в математике как универсальном языке, раскрывающем сущность мира.

Вопрос только как? По мнению А.Н. Колмогорова: «чистая математика благополучно развивается как по преимуществу наука о бесконечном. И сам основатель концепции формализованной полностью финитной математики Гильберт предпринял свой титанический труд лишь для того, чтобы обеспечить за математиками право оставаться в “канторовом парадизе” теории множеств. По-видимому, это положение вещей глубоко обосновано устройством нашего сознания, с большой легкостью оперирующего с наглядными представлениями о неограниченных последовательностях, предельных переходах, непрерывных и даже "гладких" многообразиях» [3]. 
Выборочно воспроизведем основные формулировки предложенной А.Н. Колмогоровым [3] численной модели, ориентированной на специфику развивающихся цифровых элементов вычислительных машин.

«...До недавнего времени и в математическом естествознании господствовало моделирование реальных явлений при помощи математических моделей, построенных на математике бесконечного и непрерывного. Например, изучая процесс молекулярной теплопроводности, мы представляем себе непрерывную среду, в которой температура подчинена уравнению:

$$
\frac{\partial u}{\partial t}=K\left(\frac{\partial^{2} u}{\partial x^{2}}+\frac{\partial^{2} u}{\partial y^{2}}+\frac{\partial^{2} u}{\partial z^{2}}\right)
$$

Математики привыкли рассматривать соответствующую разностную схему

$$
\Delta_{t} u=K\left(\Delta_{x x} u+\Delta_{y y} u+\Delta_{z z} u\right)
$$

лишь как возникающую при приближенном решении “точного” уравнения (1). Но реальный прочесс теплопроводности не более похож на свою непрерывную модель, выраженную уравнением (1), чем на численную модель, выраженную непосредственно уравнением (2).

Весьма вероятно, что с развитием современной вычислительной техники будет понято, что в очень многих случаях разумно изучение реальных явлений вести, избегая промежуточного этапа их стилизации в духе представлений математики бесконечного и непрерывного, переходя прямо к дискретным моделям». Полезно знать примеры для восстановления исторической справедливости, кем же было понято. «Исследованием рабочего процесса с целью определения параметров конструкций будущих изделий занимался Н.А.Дмитриев. Когда Харитон консультировался у Колмогорова по поводу использования ЭВМ, тот отвечал: “А зачем вам ЭВМ, уравнений, которые вы собираетесь решать на ЭВМ, - не существует. Нужны не ЭВМ, а алгоритмы и "модель Дмитриева". (Про Дмитриева говорили: “Он получал нужный результат, покрутив сначала ручной арифмометр “Феликс" несколько раз вперед, а потом назад”)» [6]. История знает ряд примеров «невычислимых моделей» физических процессов (Максвелла, Лапласа, Босковича, Теслы и др.).

В 1970-х появляются специализированные Вычислительные центры АН СССР, программисты, эксплуатирующие ЭВМ, и математики, не умеющие адаптировать классические математические модели для численного моделирования. В работах $[7,8,9]$ был предложен экспе- 
риментальный подход. Создание алгоритмической модели при численном анализе физических моделей на ЭВМ. Приведем несколько примеров.

1) Как и эксперимент, численная модель имеет некую физическую основу, на которой она покоится: научно разработанные программы часто содержат тысячи и десятки тысяч команд на языке высокого уровня. Практические задачи машинной обработки играют в таком случае определяющую роль. Объем памяти используемой ЭВМ, время вычисления, организация программ и даже выбранные алгоритмы зависят именно от них. Программы вычислений в метеорологии, астрофизике и даже при термоядерной реакции требуют часов, может быть, даже сотен часов вычислений на самых мощных ЭВМ. Даже простая обработка полученных результатов поднимает именно практические вопросы, не имеющие ничего общего с вопросами, занимающими теоретиков.

2) Физический эксперимент часто представляет собой некую модель действительности, которую мы и стремимся осмыслить. Если же эта действительность слишком сложна (когда эксперименты неосуществимы или слишком дороги для того, чтобы проводить их необходимое количество раз) тогда мы, естественно, стремимся к построению некоторой более простой экспериментальной модели. Таким образом, большинство физических экспериментов служит для изучения не полной проблемы, а одной из ее частных моделей. Численная модель очень напоминает эксперименты такого рода, и очень часто говорят о «численных опытах» в прикладной физике.

3) Численная модель строится, начиная с машинного представления законов, описывающих некоторую данную физическую ситуацию. Когда явления достаточно сложны, полученные результаты, как правило, отличаются от ожидаемых. Исследователь, как и специалист по информатике ${ }^{2}$, но непрограммист должен в этом случае проводить анализ, чтобы вникнуть во все детали данного явления. В эксперименте этот анализ опирается на измерения; в численном анализе мы отталкиваемся от промежуточных результатов и вычисляем вспомогательные величины (например, потоки или интегральные потери). Еще только имея общее понятие об эксперименте, уже следует подумать об анализе, который потребуется для его удачного осуществления. Аналогичным образом запись какой-либо программы должна обеспечить

\footnotetext{
${ }^{2}$ Специалист по информатике - специалист, обладающий одновременно знанием программного обеспечения ЭВМ и тех математических моделей, которые они отражают.
} 
возможность доступа к важным вспомогательным величинам. Программа без выходов так же бесполезна, как и опыт без измерений. Числовой алгоритм оказывается, таким образом, то инструментом теории, то неким типом эксперимента. На практике же решение численной модели на ЭВМ и математическая модель в теории должны рассматриваться как одинаково важные. В современных исследованиях взаимодействие между этими тремя инструментами исследования заменило диалог между теорией и экспериментом (рисунок).

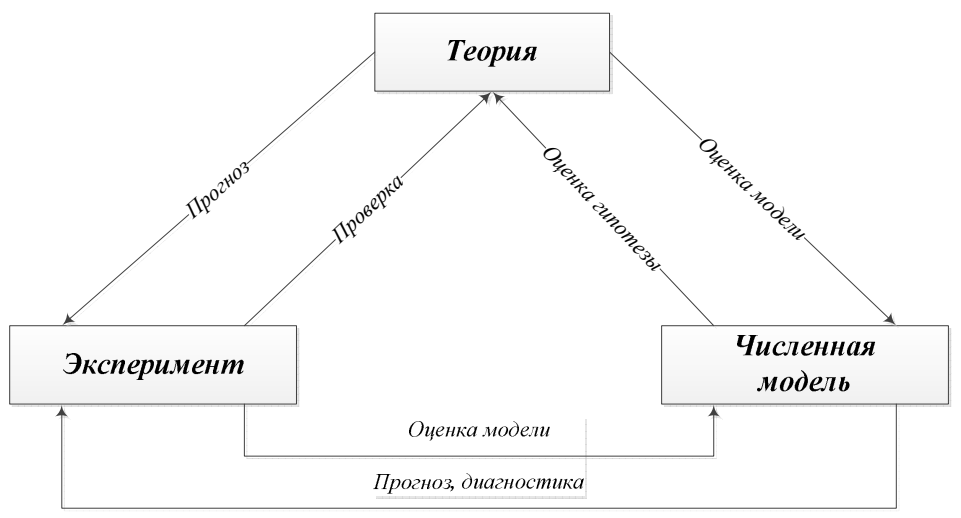

Рис. Взаимосвязь теории, экспериментов и модели.

Численная модель заимствует у теории основы машинного представления. В сложных ситуациях она апостериорно подтверждает или опровергает те или иные упрощающие гипотезы. Численная модель проверяется экспериментально, так же как и теория. В свою очередь, численная модель может использоваться как средство прогнозирования в эксперименте - в этом случае моделируются неизвестные или непроверяемые экспериментально явления, и численная модель используется для определения параметров, лучше всего приближающихся к известным результатам. Приведенная методика моделирования применяется сейчас тем шире, чем доступнее становятся вычислительные системы большой мощности, но надежды с появлением все более мощных суперкомпьютеров не улучшают прогнозирования погоды, землетрясений, тайфунов и прочих проблем. И одна из причин - отсутствие специалистов по информатике, обладающих симбиозом знаний предметной области, алгоритмическим моделированием и высококлассных программистов для суперкомпьютеров. В действитель- 
ности же высшее Российское образование производит среднетехнических программистов.

Появившийся тренд на распараллеливание с использованием многопроцессорных систем (а скорее, даже на использование автоматных сетей, как более адекватный способ распараллеливания данных) дал возможность применения имитационного моделирования [9] физических процессов и построения цифровых программируемых систем, без математического моделирования [5]. Описание физических процессов через математические уравнения применяется не одну сотню лет. Смысл этого описания в том, что физическому процессу сопоставляется некоторая функция, для которой известны соотношения между её значениями на каких-либо подмножествах. Из этих соотношений выводятся уравнения, которые рассматриваются как модель физического явления. Областью определения функции, представляющей процесс, является моделируемая физическая среда, и разбиения этой среды на малые элементы составляют функциональные соотношения между параметрами состояния этих элементов. Численная модель заимствует у теории машинное (компьютерное) представление законов, описывающих физическую ситуацию. Поэтому, если теория даёт только уравнение, то его численное решение будет имитацией физического процесса - «моделированием моделирования».

4. Информатика - глагол, а не существительное, как информация и энтропия. В основе теории колмогоровской информатики $[5,10]$ лежит следующая простая и естественная идея: сложность объекта измеряется кратчайшей длиной его записи (описания). Психологическому эксперименту - оценке сложности битовых последовательностей:

$$
\begin{aligned}
& \text { I — } 10001011101111010000 \\
& \text { II — } 01111011001101110001 \\
& \text { III - 00000000000000000000 } \\
& \text { IV - 01010101010101010101 }
\end{aligned}
$$

А.Н. Колмогоров дал такое объяснение. Цепочки (I) и (II) потому воспринимаются как случайные, что они сложны, их устройство нельзя коротко описать. А вот цепочки (III) и (IV) имеют простую, легко реализуемую запись [11]. Такое определение сложности объектов, и их уникальная идентификация (в дополнение к уже развивавшейся в то время теории сложности вычислений), была предложена Колмогоровым в начале 60-х годов XX века. И имела своей главной целью перестройку понятийной базы теории информации (на основе представления о том, что чем сложнее объект, тем больше информации он содер- 
жит). В отличие от ансамблиевой (энтропийной) оценки информации по К. Шеннону (равенства числа «кирпичей» для замка и сарая), А.Н. Колмогоров ввел понятие «“объектной информации”, физическая запись которой является одновременно ее уникальным идентификатором.

«...Стандартным способом задания информации считаем двоичные последовательности, начинающиеся с единицы:

$1,10,11,100,101,110,111,1000,1001, \ldots \gg[3]$.

Переход от понятия информации к двоичным последовательностям, которые суть данные в современной компьютерной терминологии, было воспринято научным сообществом как критерий оценки «сложности» информации, а не программы представления данных! Понятие информации интуитивно воспринимается как окончательный шаг в обработке данных (любого типа: сигнал, текст, формулы, изображения и т.д.) для принятия решения, когда семантика, содержащаяся в данных, уже извлечена. Т.е. корректно говорить о семантическом анализе как специфическом процессе обработки данных. Поэтому сочетания типа семантическая информация - это информация из информации или «масло масляное». Термин «сложность» (“complexity”) часто употребляется в смысле энтропии, т. е. сложности относительно оптимального языка, опираясь в теории алгоритмов на понятия перечислимости, вычислимости и колмогоровской сложности, пытаясь ответить на вопрос, с которым не справляется классическая теория вероятностей: определить, можно ли, например, установить взаимно однозначную идентификацию последовательностей нулей и единиц. Особенно это относится к изучению сложно организованных систем, способных перерабатывать информацию. Дискретные формы хранения и переработки информации являются основными. На них основана и сама мера “количества информации", выражаемого в “битах" числе двоичных знаков.

Колмогоров писал: «битовая форма вида записи и существование алгоритма, "перерабатывающего" запись в номер, и алгоритма, “перерабатывающего” номер в запись составляет теорию информатики (в подлиннике информации, что конфликтует с общепринятой теорией информации К. Шеннона). Из развитых вкратце общих соображений не видно, почему теория информации должна столь существенно основываться на теории вероятностей, как это представляется по большинству руководств. Моей задачей является показать, что эта зависимость от заранее созданной теории вероятностей в действи- 
тельности не является неизбежной. Ограничусь, впрочем, двумя простыми примерами:

1) основные понятия теории информатики должны и могут быть обоснованы без помощи обращения к теории вероятностей и так, что понятия «энтропия» и «количество информации» оказываются применимы к индивидуальным (идентифицируемым по Лейбницу) объектам;

2) введённые таким образом понятия теории информатики могут лечь в основу новой концепции оценки энтропийной сложности. Не справляется классическая теория вероятностей с формализацией такого интуитивно ясного термина, как «случайность», т.е. определить, можно ли, например, индивидуальную последовательность нулей и единиц считать случайной или рассматривается четыре разных подхода к этому понятию, основанных на характерных свойствах случайных последовательностей: частотоустойчивость, хаотичность, типичность и непредсказуемость. Статья, кроме незначительных редакционных изменений, была написана, когда авторы, стремясь для самих себя осмыслить понятия “вычислимая функция” и “алгоритм”, пытались пересмотреть найденные в литературе варианты определения и окончательно убедиться в том, что за ними не скрывается каких-либо возможностей расширения самого объема понятия “вычислимая функция”. Результат получился, естественно, отрицательным. Не без колебаний авторы публикуют отчет о своих поисках, так как предметно он не дает ничего нового по сравнению с более простыми определениями. По-видимому, однако, усвоенный нами подход к делу соответствует умонастроению многих математиков, которых публикация нашей статьи может избавить от повторного прохождения тех же путей сомнений и размышлений» [3].

Однако в СССР основной научный тренд применения вычислительной техники пошел по кибернетическому пути, с позиций гильбертовской математики: теории управления, общей теории связи, фильтра Р. Калмана [12]. Эта математическая модель фильтра до сих пор популярна и пользовалась спросом, особенно в СССР, при защите докторских диссертаций и у пытающихся применить его фильтр при обработке сигналов и создании систем связи и управления, без сомнений и размышлений. Несмотря даже на сомнение в его полезности самого Р. Калмана.

С точки же зрения гносеологического принципа А.Н. Колмогорова кибернетика (по Н.Л. Винеру) воспринималась как лженаука. Многие специалисты по вычислительной технике того 
времени в СССР отнеслись к обобщённому понятию «кибернетика» резко отрицательно (и даже уговорили одного философа написать в этом духе статью для очередного издания философского словаря, что послужило потом почвой для легенд о советских гонениях). Ибо прекрасно сознавали беспочвенность большей части красивых обещаний Н.Л. Винера, использовавшего название науки об управлении, придуманное А. Ампером, для собственной теории.

Огромные надежды от вычислительной техники ожидались в разнообразных исследовательских направлениях, получивших обобщённое название «кибернетика». Увы, многие обещания так и не сбылись. В частности, задача машинного перевода ещё в 1970-е годы казалась разрешимой в ближайшее время. В настоящее время можно воспользоваться компьютерным переводом и оценить, сколь далека эта система от уровня, допускающего живое общение. Или поверить, что в ближайшее время все люди станут самыми настоящими полиглотами, способными говорить на любом существующем языке мира. Компания Microsoft заявила о работе над программным обеспечением, которое будет анализировать и распознавать любую речь, конвертировать ее в необходимый язык и произносить перевод вашим же голосом. Это надежда на ветвь гаджетов информатики в стиле Билла Гейтса и Стива Джобса [13].

\section{5. Информатика и эпистемология. Гносеологический принцип} (эволюционный эпистемологический принцип) - утверждение, что в мышлении и творчестве человека проявляется только тенденция к поискам более простых (оптимальных) решений [14]. Достижение лучших решений, построенных совсем иначе, таких решений, которые не могут быть получены из предложенного путём мелких улучшений «неупростимая сложность» (irreducible complexity) лежит за пределами того, что может уловить самая изощрённая интуиция. Этот принцип был изложен в письме А.Н. Колмогорова от 27 августа 1963 г.[15] (опубликовано в 2006 г.). Экспериментальная проверка самообучения человека на моделях подтвердила истинность данного эволюционного эпистемологического принципа [14]. На Западе это направление активно развивалось в трудах К. Поппера, Р. Доукинса, Дж. Лилли, Г. Бейтсона и др. Основной тезис Дж. Лилли: «все люди, достигшие взрослого состояния, являются запрограммированными биокомпьютерами, такова человеческая природа, и этого нельзя изменить, все мы способны программировать себя и других» [16].

Грегори Бэйтсон, сопоставляя понятие информации Клода Шеннона с информатикой, отметил, что «информатика несет различие, ко- 
торое создает различие, а информация то, что реально существует только в числе (бит)». Информатика есть действие, процесс колонизации которое занимает время, а не состояние бытия, которое занимает физическое пространство, как в случае материальных предметов и принятия решения. Информатика - форма жизни, ее проживают, но ей не владеют как информацией. Это подача, а не мяч, танец, а не танцор. Даже когда она заключена в какой-либо статической форме вроде книги или жесткого диска, информация содержания является тем, что изменяет наше знание, когда мы мысленно разархивируем ее из того кода, в котором она хранится. Но, независимо от того, измеряется ли она гигабитами в секунду или словами в минуту, реальное раскодирование является процессом, который происходит в уме и при помощи ума. Г. Бейтсон начал изучать кибернетику с Н. Винером и Дж. фон Нейманом. Бейтсон сосредоточился на соотношении кибернетики и теории систем с эпистемологией и проблемами коммуникации. Ввел понятие единицы разума как кванта различимости МИНИМАЛЬНОЕ ИНФОРМАТИВНОЕ ИЗМЕНЕНИЕ: «А difference that makes a difference», — (различие определяет различие).

Информатика с очевидностью не вещь, она высвобождает из своих разнообразных вместилищ нечто подобное интерфейсу, что случается в сфере взаимодействия между умами, объектами или другими онтологическими предметными и проблемными разделами информатики. Г. Бейтсон отмечает, что отношения «организм-среда» — это «ментальный мир разума, мир обработки информации не ограничивается кожей» [10]. Разум имманентен не только «телу», но также информационным потокам вне организма или системы. Точно так же биологической единицей выживания при естественном отборе является не организм или множество организмов, как в дарвиновской теории эволюции (такой подход ведёт организм к разбалансированности отношений с окружающей средой, её разрушению, а с ней - и самого организма), но «гибкая система „организм в своей окружающей среде“». Разум имманентен не индивиду, а экосистеме или эволюционной структуре в целом [10]. Принцип «неупростимой сложности» (irreducible complexity) свидетельствует о невозможности эволюции, так как в живой и неживой природе существует множество организмов и механизмов, которые не могли бы сохранить все функции в «упрощённом» виде, чтобы потом эволюционировать в более сложные формы путём малых, случайных изменений, что подтверждается многими тысячами обнаруженных окаменелостей, показывающих, что различные организмы появлялись внезапно и в совершенно законченном ви- 
де, без эволюционных «промежуточных» форм [17]. Английский биолог и философ Ричард Доукинс предложил идею «самостей» («memes») - самовоспроизводящихся информационных структур, которые размножаются в экосистемах ума, говоря, что они подобны формам жизни (лозунги, лейблы, товарные знаки). Они и есть формы жизни во всех отношениях, за исключением отсутствия у них углеродной основы. Они самовоспроизводятся, взаимодействуют с окружением и приспосабливаются к нему, мутируют и выживают. Подобно любой другой форме жизни, они эволюционируют, заполняя ниши в своих экосистемах, каковыми являются в данном случае окружающие их системы верований и культуры. Социобиологи допускают, что формы жизни на углеродной основе являются информатикой, то есть курица является программой яйца сделать другое яйцо, и весь спектакль биологической жизни есть те средства, которыми молекула ДНК тиражирует строки не информации, а программы для воспроизводства, в точности подобные ей самой. Информатика самовоспроизводится в «трещинах» возможностей, подобно завиткам спирали ДНК, идеи - безжалостные экспансионисты, всегда ищущие новые возможности для расширения своего lebensraum («жизненного пространства» — перевод с нем.). Подобно тому, как это происходит с природными формами на углеродной основе, более выносливые организмы чрезвычайно искусны в нахождении новых мест обитания. Точно так же, как обычная домашняя муха незаметно пробралась практически во все экосистемы планеты, самость «жизнь после смерти» нашла нишу в большинстве умов или психо-экологий. Чем более широкий резонанс вызывают идея, образ или песня, тем в большее число умов они войдут и там останутся. Остановить распространение действительно жизнеспособной информации ничуть не легче, чем удержать пчел-убийц [18].

Не подумать ли нам о еще одном неразгаданном языке? Способ общения дельфинов остается совершенно непонятным, несмотря на почти 50-летние усилия. То, что эти интеллектуалы моря обмениваются сложной информацией, очевидно, но их язык щелчков и свистов для нас бессмысленнее коровьего мычания, потому что мы не знаем ключа к нему, самого принципа его построения.

Дельфины общаются не словами в нашем человеческом понимании, а звуковыми образами объектов и процессов. Ведь при переговорах они используют тот же ультразвуковой локатор, который сообщает им пространственную информацию. Посылая зондирующие импульсы и воспринимая отраженные, дельфины как бы видят. Поэтому их звуковые сигналы (для нас чисто временные) эквивалентны нашим зри- 
тельным, то есть пространственным образам. Воспроизводя такие сигналы, которые можно назвать звуковыми голограммами, дельфины посылают друг другу как бы непосредственные звуко- видео- образы, возникающие в их мозге. В отличие от человеческого, язык дельфинов - пространственно-временной. И его в принципе нельзя передать человеческой речью или ее записью (хотя смысл сообщений должен поддаваться интерпретации). Заметим, что проблема информационной безопасности решается на «физиологическом» уровне (различные свойства сред коммуникации). Важна не пропускная способность канала, а трансформация свойств коммуникации физической природы в свойства ментализма (силы мысли) биологической природы.

6. Заключение. Проблемы компиляций и прав интеллектуальной собственности сформулировал автор «Декларации о независимости» Томас Джефферсон (1743-1826):

«Если природа создала нечто, чем ты не можешь обладать в большей степени, нежели другие, то это благодаря воздействию мыслительной силы, именуемому идеей, каковая принадлежит человеку лишь до тех пор, пока он хранит ее при себе; но стоит только ее огласить, как она становится всеобщим достоянием, и тот, кому она достанется, уже не может отделять себя от нее. Особенность ее заключается также в том, что каждый обладает не какой-то ее частью, но владеет ею целиком. И тот, кому досталась от меня моя идея, воспринимает ее сам, не умаляя при этом меня; не тень, но отблеск света отбрасывает он на меня. Идеи должны беспрепятственно передаваться от одного к другому по всему земному шару для морального и взаимного наставления человека и улучшения его состояния, кажется, было нарочито благосклонно задумано природой, когда она сделала их распространяющимися, подобно огню, по всему пространству без уменьшения их плотности в любой точке, и подобно воздуху, в котором мы дышим, двигаемся и имеем свое физическое существование и который не может быть ограничен или составлять исключительную собственность. Изобретения по самой своей природе не могут быть предметом собственности».

\section{Литература}

1. Музиль Р. Человек без свойств. Перевод С. Апт: Издательство «Эксмо», Москва, $2008.1088 \mathrm{c}$.

2. Научная школа «Алгоритмические модели цифровой программируемой технологии развивающихся инфокоммуникационных систем». // Информационноизмерительные и управляющие системы, №5, т. 10, 2012. 70 с.

3. Колмогоров А.Н. Теория информации и теория алгоритмов. М.: Наука, 1987. 304 с. 
4. Войцехович В.Э. Господствующие стили математического мышления. // Стили в математике: социокультурная философия математики/ Под ред. А.Г. Барабашева. СПб, 1999. с.503-504.

5. Александров В.В., Кулешов С.В., Цветков О.В. Цифровая технология инфокоммуникации. Передача, хранение и семантический анализ текста, звука, видео. СПб.: Наука, 2008. 244 с.

6. Газета «Завтра». [Электронный ресурс]. - Доступ: http://zavtra.ru/content/view/istoriya-bombyi-prosta-2013-01-23-000000/

7. Пономарев B.М., Александров В.В. Алгоритмическая модель как средство автоматизации исследований. В книге «Автоматизация исследований и проектирования». Изд. «Наука», Москва, 1978. с.5-12.

8. Жаблон К., Симон Ж.-К. Применение ЭВМ для численного моделирования в физике // Перевод с французского А.В.Арсентьевой. Под редакцией В.В. Александрова и Ю.С. Вишнякова. Москва: «Наука», 1983. 240 с.

9. Александров B.B., Сойгин А.М. Метод прямого компьютерного моделирования. Препринт № 102, Л.: ЛИИАН, 1989. 23 с.

10. Бейтсон Г. Форма, вещество и различие // Бейтсон Г. Экология разума. М., 2000.

11. Успенский B.A. Четыре алгоритмических лица случайности. // Математическое просвещение, сер. 3, вып. 10, 2006. С. 71-108.

12. Калман Р. Открытие или изобретение: Ньютонианская революция в технологии систем // Авиакосмическое приборостроение, 2004, № 6.

13. Александров B.В. Стив Джобс vs Билл Гейтс. // Информационно-измерительные и управляющие системы, №11, т.9, 2011. С. 3-6

14. Ливщии B. Гносеологический принцип Колмогорова. [Электронный ресурс]. Доступ: http://www.proza.ru/2012/06/29/1346

15. Письмо академика Колмогорова (А.Н. Колмогоров. 27 августа 1963 г.). [Электронный ресурс]. - Доступ: http://www.psychology-online.net/articles/doc-142.html

16. Лилли Дж. Программирование и метапрограммирование человеческого биокомпьютера. Пер. с англ. К.: «София», Ltd., 1994. 320 с.

17. Будзилович П. Живая клетка - миниатюрное чудо Творца. [Электронный ресурс]. — Доступ: http://www.russia-talk.org/cd-history/evolution/evo-denton.htm

18. Барлоу Дж.П. Продажа вина без бутылок: экономика сознания в глобальной Сети. [Электронный pecypc]. - Доступ: http://www.knigi.ws/avan/2871-dzhon-barlouprodazha-vina-bez-butylok-jekonomika.html

Александров Виктор Васильевич - докт. техн. наук, заведующий лабораторией автоматизации научных исследований Федерального государственного бюджетного учреждения науки Санкт-Петербургского института информатики и автоматизации РАН (СПИИРАН). Область научных интересов: теоретические основы информатики, инфокоммуникационные системы, обработка видеоданных. Число научных публикаций более 350. alexandr@iias.spb.su, sial.iias.spb.su; СПИИРАН, 14-я линия В.O., 39, СанктПетербург, 199178, РФ; р.т. +7(812)323-5139, факс +7(812)328-4450.

Alexandrov Victor Vasil'evich - Doctor in Tech. Sc., Head of Laboratory of Research Automation SPIIRAS. Research interest: theoretical basis of informatics, infology information systems, infocommunication systems, video data streams processing. The number of publication - more than 350. alexandr@iias.spb.su, sial.iias.spb.su; SPIIRAS, 14-th Line V.O., 39, St. Petersburg, 199178, Russia; office phone +7(812)323-5139, fax +7(812)328-4450.

Рекомендовано лабораторией автоматизации научных исследований СПИИРАН. Статья поступила в редакцию 10.03.2013 


\section{PEФEPAT}

\section{Александров В.B. Математика. Кибернетика. Информатика.}

В настоящее время во многих областях знания, связанных с информационными технологиями, происходит смена парадигмы от традиционных математических моделей теории управления к алгоритмической теории информатики, основанной на теории А.Н. Колмогорова. В связи с этим необходимо сопоставление между идентифицируемой объектной информацией и ансамблевой (энтропийной) информацией по Шеннону.

Численная модель заимствует у теории основы машинного представления. В сложных ситуациях она апостериорно подтверждает или опровергает те или иные упрощающие гипотезы. Численное моделирование применяется тем шире, чем доступнее становятся вычислительные системы большой мощности, но не всегда обеспечивает улучшение в прогнозировании погоды, землетрясений, тайфунов и прочих проблем. И одна из причин - отсутствие специалистов по информатике, обладающих симбиозом знаний предметной области и алгоритмическим моделированием, а также высококлассных программистов для суперкомпьютеров.

Появившийся тренд на распараллеливание с использованием многопроцессорных систем (а скорее, даже на использование автоматных сетей, как более адекватный способ распараллеливания данных) дал возможность применения имитационного моделирования физических процессов и построения цифровых программируемых систем, без математического моделирования. Поэтому, если теория даёт только уравнение, то его численное решение будет имитацией физического процесса — «моделированием моделирования».

Информатика - глагол, а не существительное, как информация и энтропия. Понятие информации интуитивно воспринимается как окончательный шаг в обработке данных любого типа для принятия решения, когда семантика, содержащаяся в данных, уже извлечена, т.е. корректно говорить о семантическом анализе как специфическом процессе обработки данных.

В мышлении и творчестве человека проявляется только тенденция к поискам более простых (оптимальных) решений как эволюционный эпистемологический принцип. Г. Бэйтсон, сопоставляя понятие информации К. Шеннона с информатикой, отметил, что «информатика несет различие, которое создает различие, а информация то, что реально существует только в числе (бит)». Информатика есть действие, которое занимает время, а не состояние бытия, которое занимает физическое пространство.

Проблема информационной безопасности решается на «физиологическом» уровне (различные свойства сред коммуникации). Важна не пропускная способность канала, а трансформация свойств коммуникации физической природы в свойства ментализма (силы мысли) биологической природы. 


\section{SUMMARY}

\section{Alexandrov V.V. The Mathematics. The Cybernetics. The Informatics.}

Nowadays, many fields of knowledge related to information technologies are experiencing paradigm shift from traditional mathematical models of control theory to algorithmic information theory based on A. N. Kolmogorov. Due to this the comparison between identifiable object information and Shannon's ensemble (entropy) information is needed.

Numerical model borrows the basis of machine representation from theory. In complex cases it a posteriori confirms or rejects various simplification hypothesis. Numerical modeling applications increase with increasing of computation power, but not necessarily it improves weather, earthquakes, typhoons and similar disasters forecasting. The one of the reasons for this - the absence of information specialists possessing the symbiosis of subject domain knowledge and algorithmic modeling and also absence of hi class programmers for super computers.

The emergence of paralleling trend using multiple processors (or more likely even the automates networks for more efficient paralleling) had enabled the possibility to apply imitation modeling of physical processes and developing of programmed systems without mathematical modeling. Thus, if theory gives only the equation than it's numerical solution will be the imitation of physical process "the modeling of the modeling".

The informatics is a verb, not a noun like information and entropy. The notion of information is intuitively being perceived as final step in data processing of any kind for decision making when semantic content of data has already been extracted thus it is correct to speak about semantic analysis as a specific data processing.

In thinking and creativity processes of human beings the only tendency which emerges - is a search for more simple (optimal) solutions as a an evolution epistemology principle. G. Bateson while comparing Shannon's notion of information with the informatics had noted that "informatics brings difference which creates difference, and the information brings what is really exists only in number (bit)". Informatics is an action thats takes some time and not a state of being which occupies physical space.

The problem of information security is being solved on «physiology» level (different properties of communication media). The important part is not a channel bandwidth but the transformation of communication properties of physical nature to the properties of mentalism (the power of thought) of biological nature. 